MARTINS, Urá Lobato; BAPTISTA, Vinicius Ferreira. A adoção do Recall como instrumento de ampliação do controle popular dos mandatos políticos. Revista Eletrônica Direito e Política, Programa de Pós-Graduação Stricto Sensu em Ciência Jurídica da UNIVALI, Itajaí, v.13, n.2, $2^{\circ}$ quadrimestre de 2018. Disponível em: www.univali.br/direitoepolitica - ISSN 1980-7791

\title{
A ADOÇÃO DO RECALL COMO INSTRUMENTO DE AMPLIAÇÃO DO CONTROLE POPULAR DOS MANDATOS POLÍTICOS
}

\author{
ADOPTION OF RECALL AS MECHANISM OF SOCIAL CONTROL OF POLITICAL \\ MANDATES
}

\section{Urá Lobato Martins ${ }^{1}$}

Vinicius Ferreira Baptista

SUMÁRIO: Introdução; 1 Origem e delimitação conceitual do Recall; 2 Aplicação do instituto do Recall no Brasil como instrumento de ampliação do controle popular dos mandatos políticos; Considerações Finais; Referência das fontes citadas.

\section{RESUMO}

O objetivo deste artigo é discutir o instituto do recall como mecanismo constitucional de avaliação de mandatos políticos, assegurando o controle social. Em um primeiro momento, delimitamos conceitualmente o instituto do Recall, destacando as experiências democráticas de países como Venezuela, Equador, Peru, Colômbia, a Província de Córdoba (Argentina), Bolívia e Cuba. Posteriormente, apresentamos a proposta da aplicação do instituto do recall no Brasil, levantando as principais peças legislativas e proposições legais pertinentes ao tema. Ao fim, realizamos uma reflexão da proposta, na medida em que analisamos possibilidades de aproximações e estranhamentos na conjuntura política brasileira. Situamos que o instituto do recall deve ser afastado dos Poderes Legislativo e Executivo de forma a não ter o processo viciado devido à conjuntura histórica brasileira negativa de agentes políticos.

Palavras-chave: Democracia; recall; controle popular; mandatos políticos.

\section{ABSTRACT}

The purpose of this article is to discuss the institute of recall as a constitutional mechanism for evaluating political mandates, ensuring social control. At first, conceptually we delimit the institute of Recall, highlighting the democratic experiences of countries as Venezuela, Ecuador, Peru, Colombia, Cordoba Province (Argentina), Bolivia and Cuba. Subsequently we present the proposed application of institute in Brazil, raising the main pieces of legislation and legal propositions to

${ }^{1}$ Doutora em Políticas Públicas e Formação Humana pela Universidade do Estado do Rio de Janeiro (UERJ). Mestre em Direito pela Universidade Federal do Pará (UFPA). Advogada. Rio de Janeiro, RJ, Brasil. E-mail: uramartins@ig.com.br

2 Doutor em Políticas Públicas e Formação Humana pela Universidade do Estado do Rio de Janeiro (UERJ). Professor Adjunto do Departamento de Administração Pública e do Programa de PósGraduação em Desenvolvimento Territorial e Políticas Públicas da Universidade Federal Rural do Rio de Janeiro (UFRRJ). Seropédica, Rio de Janeiro, Brasil. E-mail: viniciusferbap2007@hotmail.com 
MARTINS, Urá Lobato; BAPTISTA, Vinicius Ferreira. A adoção do Recall como instrumento de ampliação do controle popular dos mandatos políticos. Revista Eletrônica Direito e Política, Programa de Pós-Graduação Stricto Sensu em Ciência Jurídica da UNIVALI, Itajaí, v.13, n.2, $2^{\circ}$ quadrimestre de 2018. Disponível em: www.univali.br/direitoepolitica - ISSN 1980-7791

the topic. At the end, we conducted a reflection of the proposal, as we analyze possibilities of approaches and strangeness in the Brazilian political conjuncture. Situate the institute of recall should be away from the Legislative and Executive branches in order to not have a flawed process due to the negative Brazilian historical conjuncture of political agents.

Keywords: Democracy, recall, popular control; political mandates

\section{INTRODUÇÃO}

A concepção de participação popular direta tal qual a conhecemos sofreu, ao longo do tempo, uma inevitável transformação conceitual e prática em suas bases. $\mathrm{Na}$ medida em que a participação política é um valor, tem-se que a mesma apresenta graus de alcance de mecanismos e de participação intrínseca em si. Há uma ligação entre a participação, a decisão política e a legitimação. Nesta discussão, a legitimidade do processo decisório, da tomada de decisão e das decisões políticas situa que a legitimação e a participação política dependem não somente de um espaço aberto e público para a esta última, mas também de mecanismos institucionalizados que sejam conhecidos e abertos; de ferramentas institucionais que provejam instrumental prático e efetivo de participação e deliberação; mas, acima de tudo, é imperativo a existência de regras claras e institucionalizadas que pautem as Instituições em si e a legalidade do processo num sentido mais amplo. O crescente envolvimento de diversos grupos na concepção e na implementação, desde políticas públicas até desenvolvimento de projetos e de processos, assim como de fiscalização da produtividade e resultados de mandatos de parlamentares, tem consequências para o entendimento e a avaliação dos processos democráticos.

Os mecanismos de participação popular direta são necessários, mas insuficientes se não são fomentados e ampliados, e não restritos aos jogos e disputas políticas do sistema político-institucional, no sentido mais amplo e, principalmente, se não são garantidos constitucionalmente. As Instituições são base para legitimação do processo, que deve ser aberto e participativo. A participação envolve uma razão e uma necessidade: a busca pela legitimidade e que as decisões sejam fruto da negociação em espaços discursivos sobre os rumos da decisão política. Com a Democracia Deliberativa tenta-se um meio-termo no sentido de ter-se uma participação plena, porém viável. Claro que, neste sentido, nem tudo pode ser 
MARTINS, Urá Lobato; BAPTISTA, Vinicius Ferreira. A adoção do Recall como instrumento de ampliação do controle popular dos mandatos políticos. Revista Eletrônica Direito e Política, Programa de Pós-Graduação Stricto Sensu em Ciência Jurídica da UNIVALI, Itajaí, v.13, n.2, $2^{\circ}$ quadrimestre de 2018. Disponível em: www.univali.br/direitoepolitica - ISSN 1980-7791

decidido por todos em todo momento. O que se tem como objetivo é a consideração coletiva sobre os rumos das decisões políticas que afetam a esfera pública e a vida social.

Tendo em vista esta perspectiva, apresentamos o instituto do Recall, como instrumento de ampliação do controle popular dos mandatos políticos de agentes públicos eleitos diretamente em eleições. Em um primeiro momento, delimitamos conceitualmente o instituto do Recall, destacando as experiências democráticas de países como Venezuela, Equador, Peru, Colômbia, a Província de Córdoba (Argentina), Bolívia e Cuba. Posteriormente, apresentamos a proposta da aplicação do instituto do recall no Brasil, levantando as principais peças legislativas e proposições legais pertinentes ao tema. Ao fim, realizamos uma reflexão da proposta, na medida em que analisamos possibilidades de aproximações e estranhamentos na conjuntura política brasileira.

\section{ORIGEM E DELIMITAÇÃO CONCEITUAL DO RECALL}

A participação contínua da sociedade na gestão pública é um direito assegurado pela Constituição Federal de 1988, permitindo que os cidadãos participem da formulação das políticas públicas e da fiscalização permanente da aplicação dos recursos públicos. A participação do cidadão na Administração Pública não se refere apenas à possibilidade de escolha daqueles que exercerão mandato público eletivo com tempo determinado, mas, também, de acompanhar sistematicamente, durante todo o mandato supervisionado, o exercício deste poder delegado avaliando a tomada de decisão e resultados decorrentes da mesma.

O controle social pode ser entendido como a participação do cidadão na gestão pública ao fiscalizar, monitorar e controlar as ações da Administração Pública em seus diferentes níveis, compreendendo um instrumento de construção, fortalecimento e ampliação da Cidadania ao aproximar a Sociedade do Estado.

Os mecanismos de controle na Administração Pública não compreendem a participação direta da população no que toca, especificamente quanto à fiscalização do cumprimento do mandado de agentes públicos eleitos democraticamente. Esta participação se dá apenas pela via indireta associada aos 
MARTINS, Urá Lobato; BAPTISTA, Vinicius Ferreira. A adoção do Recall como instrumento de ampliação do controle popular dos mandatos políticos. Revista Eletrônica Direito e Política, Programa de Pós-Graduação Stricto Sensu em Ciência Jurídica da UNIVALI, Itajaí, v.13, n.2, $2^{\circ}$ quadrimestre de 2018. Disponível em: www.univali.br/direitoepolitica - ISSN 1980-7791

Conselhos Municipais, Tribunais de Contas e Controladoria Geral da União, por exemplo, onde a população tem acesso às análises dos referidos órgãos sem, todavia, ter possibilidade de deliberação efetiva sobre os resultados oriundos de tais análises.

O instituto do recall é oriundo do sistema norte-americano, sendo que nos Estados Unidos, conforme ensina Ávila ${ }^{3}$, o recall garante uma maior aproximação entre eleitores e eleitos, visto que o sistema eleitoral adotado facilita tal proximidade, em função de ser o majoritário por distritos. Dessa forma, o referido autor ressalta essa característica da Federação norte-americana, qual seja, a autonomia política dos Estados federados, sendo que o recall é previsto apenas nos níveis estaduais e municipais, não existindo previsão no âmbito federal.

Há, segundo o referido autor, uma ampla variação de sujeitos que podem sofrer a penalidade decorrente do recall no sistema americano, abrangendo, inclusive, diretores de escola e qualquer servidor público:

Nos Estados Unidos, especificamente, o instituto é um mecanismo consistente de controle, e dependendo do Estado da Federação, há previsão de sua utilização para destituição de autoridades do Executivo, Legislativo e Judiciário, diretores de escola e até mesmo qualquer servidor público, mesmo que não ocupe cargo efetivo. Essa ampla variação de sujeitos que podem ser submetidos ao mecanismo é um fenômeno típico da sociedade norte-americana, uma vez que os Estados têm autonomia para decidirem, da forma que Ihes for mais conveniente, quem pode ser submetido ao recall e quais são as hipóteses em que ele pode ser aplicado ${ }^{4}$.

Bonavides $^{5}$, por sua vez, diferencia o recall (revogação individual) da Abberufungsrecht (revogação coletiva), explicando que, no primeiro caso, o eleitorado destitui funcionários que lhe desagradam, enquanto que no caso da revogação coletiva, não há revogação do mandato de apenas um indivíduo, mas

\footnotetext{
3 ÁVILA, Caio Márcio de Brito. Recall - a revogação do mandato político pelos eleitores: uma proposta para o sistema jurídico brasileiro. 2009. 152 f. Tese (Doutorado em Direito) Faculdade de Direito, Universidade de São Paulo, São Paulo, 2009.

4 ÁVILA, Caio Márcio de Brito. Recall - a revogação do mandato político pelos eleitores: uma proposta para o sistema jurídico brasileiro. p. 72.

5 BOnAVIDES, Paulo. Ciência Política. 18 ed. São Paulo: Malheiros, 2011.
} 
MARTINS, Urá Lobato; BAPTISTA, Vinicius Ferreira. A adoção do Recall como instrumento de ampliação do controle popular dos mandatos políticos. Revista Eletrônica Direito e Política, Programa de Pós-Graduação Stricto Sensu em Ciência Jurídica da UNIVALI, Itajaí, v.13, n.2, $2^{\circ}$ quadrimestre de 2018. Disponível em: www.univali.br/direitoepolitica - ISSN 1980-7791

sim, de toda assembleia, após participação de considerável percentagem constitucional de eleitores, demonstrando, assim, que tal corpo legislativo carece de confiança popular.

Além disso, Dallari ${ }^{6}$ ensina que o recall americano também pode ser utilizado para modificar uma decisão judicial, embora seja um instituto controvertido:

O recall judicial, bastante controvertido, foi preconizado por THEODORE ROOSEVELT, em 1912, numa de suas campanhas eleitorais. Segundo sua proposição, as decisões de juízes e Tribunais, excluída apenas a Suprema Corte, negando a aplicação de uma lei por julgá-la inconstitucional, deveriam poder ser anuladas pelo voto da maioria dos eleitores. Ocorrida essa anulação a lei seria considerada constitucional, devendo ser aplicada. Inúmeros Estados acolheram o recall judicial em suas respectivas Constituições, visando, sobretudo, a superar os obstáculos à aplicação de leis sociais, opostos pela magistratura eletiva pressionada pelos grupos econômicos que decidiam as eleições. Apontam-se, entretanto, muitos inconvenientes em todas as modalidades de recall, razão pela qual seu uso é relativamente raro, devendo-se notar que os parlamentares, a quem caberia aperfeiçoar esse instituto, preferem eliminá-lo para não ficarem sujeitos aos seus efeitos ${ }^{7}$.

Corroborando, Ávila apresenta os argumentos favoráveis e contrários ao recall judicial:

Há argumentos contra e a favor do recall judicial. De um lado, há a alegação de que não se deve envolver o juiz no centro dos baixos interesses políticos, sob pena de suprimir-lhe a independência e autoridade. De outro lado, há a alegação de que a lógica da democracia semidireta leva à adoção do recall, pois se o povo pode evitar as más leis por meio de referendo e obter boas leis por meio de iniciativa popular, os resultados desses procedimentos poderiam ser frustrados, caso não fosse permitida a revogação da decisão judicial que

${ }^{6}$ DALLARI, Dalmo de Abreu. Elementos de Teoria Geral do Estado. 25. ed. atual. São Paulo: Saraiva, 2005.

7 DALLARI, Dalmo de Abreu. Elementos de Teoria Geral do Estado. 25. ed. atual. São Paulo: Saraiva, 2005. p. 155. 
MARTINS, Urá Lobato; BAPTISTA, Vinicius Ferreira. A adoção do Recall como instrumento de ampliação do controle popular dos mandatos políticos. Revista Eletrônica Direito e Política, Programa de Pós-Graduação Stricto Sensu em Ciência Jurídica da UNIVALI, Itajaí, v.13, n.2, $2^{\circ}$ quadrimestre de 2018. Disponível em: www.univali.br/direitoepolitica - ISSN 1980-7791

paralisasse ou negasse aplicação aos resultados dessas decisões políticas populares ${ }^{8}$.

No âmbito da América Latina, alguns países estabelecem a possibilidade de aplicação do recall, como é o caso da Venezuela, Equador, Peru, Colômbia, Província de Córdoba (Argentina), Bolívia e Cuba.

A Constituição da República Bolivariana da Venezuela de 1999 estabelece a possibilidade de revogação de mandatos, mediante referendo revocatório, com aplicação a todos os cargos eletivos, de acordo com seus artigos 6, 70, 72, 197, 198 e 233, desde que seja respeitado o seguinte limite temporal: o pedido de revogação não pode ser realizado antes da primeira metade do mandato.

O art. 72 da Constituição da Venezuela, por sua vez, estabelece que o quórum para solicitar convocação de um referendo para revogar o mandato deverá ser equivalente a $20 \%$ dos eleitores, através do seguinte procedimento.

Artigo 72. Artículo 72. Todos los cargos y magistraturas de elección popular son revocables. Transcurrida la mitad del período para el cual fue elegido el funcionario o funcionaria, un número no menor del veinte por ciento de los electores o electoras inscritos en la correspondiente circunscripción podrá solicitar la convocatoria de un referendo para revocar su mandato.

Cuando igual o mayor número de electores y electoras que eligieron al funcionario o funcionaria hubieren votado a favor de la revocatoria, siempre que haya concurrido al referendo un número de electores y electoras igual o superior al veinticinco por ciento de los electores y electoras inscritos, se considerará revocado su mandato y se procederá de inmediato a cubrir la falta absoluta conforme a lo dispuesto en esta Constitución y la ley.

Caso seja considerado procedente o pedido, a revogação do mandato gera direito à suplência (o Vice-Presidente Executivo e Vice-Presidente Executivo assumirá a Presidência da República para completá-lo), nos termos do art. 233 da Constituição Venezuelana.

8 ÁVILA, Caio Márcio de Brito. Recall - a revogação do mandato político pelos eleitores: uma proposta para o sistema jurídico brasileiro. p. 94. 
MARTINS, Urá Lobato; BAPTISTA, Vinicius Ferreira. A adoção do Recall como instrumento de ampliação do controle popular dos mandatos políticos. Revista Eletrônica Direito e Política, Programa de Pós-Graduação Stricto Sensu em Ciência Jurídica da UNIVALI, Itajaí, v.13, n.2, $2^{\circ}$ quadrimestre de 2018. Disponível em: www.univali.br/direitoepolitica - ISSN 1980-7791

Além disso, somente pode ser feito um pedido de revogação durante o mandato (parte final do art. 72 da Constituição Venezuelana), sendo que o político que teve o mandato revogado não será eletivo para cargo político no próximo período (art. 198 da Constituição Venezuelana).

No caso do Equador, a Constituição Equatoriana de 2008 prevê em seus artigos $61,105,106$ e 145 o direito de revogar os mandatos de todas autoridades eleitas.

O art. 105 da referida Constituição estabelece como vedação temporal que o pedido de revogação não pode ocorrer antes do primeiro ano do mandato, nem tampouco no último ano. Além disso, o referido artigo determina que somente pode ser feito um pedido de revogação durante o mandato.

No que se refere ao quórum de convocação, o art. 105 da Constituição do Equador estabelece o percentual mínimo de $10 \%$ dos eleitores, sendo que no caso de Presidente da República, é necessário percentual não inferior a 15\%.

O referendo revocatório deve ocorrer no prazo de 60 dias, com votação de maioria absoluta de votos válidos, sendo que no caso de revogação do Presidente da República, é necessário a maioria absoluta dos eleitores. Caso procedente, ocorrerá a suplência, com a substituição autoridade nos termos da Constituição (art. 106 da Constituição do Equador).

No caso do Peru, a Constituição de 1993 faz menção ao direito de remoção ou revogação de autoridades em seus art. $31^{9}$.

Nessa linha, a Constituição da Colômbia de 1991 prevê em seu art. 40, item 4, i direito de revogar os mandatos dos funcionários eleitos. Tal direito foi regulamentado pela Lei n. 134/1994, em seu art. 64 (alterado pela Lei n. 741 de 2002), estabelece o quórum de $40 \%$ dos votos válidos, sendo que a revogação alcança apenas governadores e prefeito, podendo a revogação ocorre apenas uma

\footnotetext{
9 Artículo 310. Los ciudadanos tienen derecho a participar en los asuntos públicos mediante referéndum; iniciativa legislativa; remoción o revocación de autoridades y demanda de rendición de cuentas. Tienen también el derecho de ser elegidos y de elegir libremente a sus representantes, de acuerdo con las condiciones y procedimientos determinados por ley orgánica.
} 
MARTINS, Urá Lobato; BAPTISTA, Vinicius Ferreira. A adoção do Recall como instrumento de ampliação do controle popular dos mandatos políticos. Revista Eletrônica Direito e Política, Programa de Pós-Graduação Stricto Sensu em Ciência Jurídica da UNIVALI, Itajaí, v.13, n.2, $2^{\circ}$ quadrimestre de 2018. Disponível em: www.univali.br/direitoepolitica - ISSN 1980-7791

vez durante o mandato, respeitando o limite temporal de 1 ano para que possa ser solicitado.

No caso da Colômbia, há algumas peculiaridades, como a necessidade de motivação (insatisfação geral dos cidadãos ou pelo não cumprimento de programa de governo $)^{10}$.

Caso seja aprovada a revogação do mandato, deve ocorrer novos eleições no prazo de 30 dias, sendo que durante o período entre a revogação e a posse do novo presidente, assumirá um cidadão que pertença ao mesmo grupo, partido ou movimento político do presidente que teve mandato revogado ${ }^{11}$.

Na Argentina não há previsão no âmbito nacional, mas o instituto do recall, é encontrado na Constituição da Província de Córdoba de 1987, no art. 183, item 4, denominado de direito de revocatória ${ }^{12}$.

No ano de 2009, a população da Bolívia ratificou a nova Constituição que instituiu um Estado plurinacional, mediante referendo realizado no dia 25 de janeiro de 2009, dentre vários direitos, o art. 11, inciso II, item 1 estabelece o instituto da revogação de mandato, sendo delineado nos artigos 157, 170, 171,195, 240 e 286 da referida Constituição.

Caso o Presidente ou governador seja afastado, o art. 171 da Constituição da Bolívia estabelece que assumirá a presidência o Vice, que deverá convocar de

\footnotetext{
${ }^{10}$ Artículo 650.- Motivación de la revocatoria. El formulario de solicitud de convocatoria a la votación para la revocatoria, deberá contener las razones que la fundamentan, por la insatisfacción general de la ciudadanía o por el incumplimiento del programa de Gobierno. In: COLÔMBIA. Lei 134/1994. Estabelece regras em matéria de mecanismos de participação cidadã são dadas

11 "Artículo 740.- Elección del sucesor. Revocado el mandato a un gobernador o a un alcalde se convocará a elecciones para escoger al sucesor, dentro de los treinta (30) días siguientes a la fecha en que el Registrador correspondiente certificare los resultados de la votación.

Durante el período que transcurra entre la fecha de la revocatoria y la posesión del nuevo mandatario, será designado en calidad de encargado por el Presidente de la República o el gobernador, según el caso, un ciudadano del mismo grupo, partido o movimiento político del mandatario revocado." (COLÔMBIA, Lei n. 134/1994).

12 "Artículo 183. Las Cartas Orgánicas deben asegurar: (...) 4. Los derechos de iniciativa, referéndum y revocatória." (CÓRDOBA, Constituição de 1987).
} 
MARTINS, Urá Lobato; BAPTISTA, Vinicius Ferreira. A adoção do Recall como instrumento de ampliação do controle popular dos mandatos políticos. Revista Eletrônica Direito e Política, Programa de Pós-Graduação Stricto Sensu em Ciência Jurídica da UNIVALI, Itajaí, v.13, n.2, $2^{\circ}$ quadrimestre de 2018. Disponível em: www.univali.br/direitoepolitica - ISSN 1980-7791

imediato novas eleições, que deverá ocorrer no prazo máximo de 90 (noventa) dias.

Além disso, podem sofrer o recall toda pessoa que exerce uma autoridade eleita, com exceção do Poder Judiciário, desde que o pedido de revogação do mandato seja realizado há pelo menos metade do período do mandato, não podendo ser feito durante o último ano (art. 240, II, da Constituição da Bolívia).

A Constituição de Cuba de 1976 estabelece, em seu art. 68, item 3, que os "eleitos têm o dever de prestar contas de suas ações e pode ser destituído do cargo a qualquer tempo".

A Lei Cubana n. 89 de 1999 regulamenta o procedimento da revogação do mandato, estabelecendo os seguintes motivos que podem dar ensejo a tal procedimento:

ARTÍCULO 5: Procede la revocación del mandato por existir alguna de las causales siguientes:

a) incumplimiento reiterado de las obligaciones derivadas del mandato conferido;

b) incurrir en hechos que lo hagan desmerecer de buen concepto público; y

c) manifestar una conducta incompatible con el honor de ser representante del pueblo en un órgano del Poder Popular" (CUBA, Lei n. 89/1999).

Ao analisar a adoção do recall por países latino-americanos, Souza e Vieira destacam o seguinte:

Comum a esses países latino-americanos é a cláusula de vedação temporal para a realização de recall. Como visto, esse elemento é dotado de extrema relevância para fins de mitigação dos efeitos sistêmicos do acionamento indiscriminado do mecanismo, tanto à luz da estabilidade política como dos respectivos custos materiais. Algo que não é previsto no estado da Califórnia. Portanto, antes do primeiro ano de mandato, ou mesmo da primeira metade (Venezuela e Bolívia), assim como no último ano (Equador e Bolívia), não é permitido deflagrar-se o procedimento revocatório ${ }^{13}$.

13 SOUZA, Raphael Ramos Monteiro; VIEIRA, José Ribas. Recall, democracia direta e estabilidade institucional. Revista de Informação legislativa, v. 51, n. 202, p. 43-57, abr./jun. 2014. p. 49 
MARTINS, Urá Lobato; BAPTISTA, Vinicius Ferreira. A adoção do Recall como instrumento de ampliação do controle popular dos mandatos políticos. Revista Eletrônica Direito e Política, Programa de Pós-Graduação Stricto Sensu em Ciência Jurídica da UNIVALI, Itajaí, v.13, n.2, $2^{\circ}$ quadrimestre de 2018. Disponível em: www.univali.br/direitoepolitica - ISSN 1980-7791

Dessa forma, embora apresentem algumas diferenças com relação à aplicação e delimitação do instituto do recall, a adoção de tal prática pelos países citados demonstra um fortalecimento do controle popular, na medida em que o povo poderá repudiar, através de meios institucionalizados, os políticos que não cumprirem sua plataforma política ou adotem medidas que causem prejuízo ao povo.

A seguir, serão apresentadas as propostas legislativas realizadas no âmbito do Brasil, sendo discutidos algumas questões problemáticas, considerando a conjuntura política brasileira.

\section{APLICAÇÃO DO INSTITUTO DO RECALL NO BRASIL COMO INSTRUMENTO DE AMPLIAÇÃO DO CONTROLE POPULAR DOS MANDATOS POLÍTICOS}

Segundo Dallari ${ }^{14}$, os mecanismos de participação popular mais utilizados são: referendo, plebiscito, iniciativa popular, recall e veto popular. No entanto, o Brasil optou por apenas três desses instrumentos, quais sejam: referendo, plebiscito e iniciativa popular, nos termos do art. 14 da Constituição Federal.

Atualmente, a perda do mandato dos representantes políticos apenas pode ocorrer através do impeachment, o que requer autorização da Câmara dos Deputados, por 2/3 (dois terços) de seus membros, cabendo ao Senado Federal processar e julgar o Presidente da República, no caso de crimes de responsabilidade.

Além disso, o Presidente da República responderá pelos crimes comuns cometidos no exercício da função, sendo que sua prisão somente pode ocorrer desde que haja sentença condenatória proferida pelo Supremo Tribunal Federal, nos termos do art. 86, § 30, da Constituição Federal, que estabelece: "enquanto não sobrevier sentença condenatória, nas infrações comuns, o Presidente da República não estará sujeito a prisão".

\footnotetext{
14 DALLARI, Dalmo de Abreu. Elementos de Teoria Geral do Estado. 25. ed. atual. São Paulo: Saraiva, 2005.
} 
MARTINS, Urá Lobato; BAPTISTA, Vinicius Ferreira. A adoção do Recall como instrumento de ampliação do controle popular dos mandatos políticos. Revista Eletrônica Direito e Política, Programa de Pós-Graduação Stricto Sensu em Ciência Jurídica da UNIVALI, Itajaí, v.13, n.2, 20 quadrimestre de 2018. Disponível em: www.univali.br/direitoepolitica - ISSN 1980-7791

No julgamento do Mandado de Segurança n. 21.689, ficaram bem delimitadas as mudanças que ocorreram nas leis que regularam o processo de impeachment:

O impeachment, no Brasil, a partir da Constituição de 1891, segundo o modelo americano, mas com características que o distinguem deste: no Brasil, ao contrário do que ocorre nos Estados Unidos, lei ordinária definirá os crimes de responsabilidade, disciplinará a acusação e estabelecerá o processo e o julgamento. Alteração do direito positivo brasileiro: a Lei 27, de 1892, art. 30, estabelecia: a) 0 processo de impeachment somente poderia ser intentado durante o período presidencial; b) intentado, cessaria quando o presidente, por qualquer motivo, deixasse definitivamente o exercício do cargo. A Lei 1.079, de 1950, estabelece, apenas, no seu art. 15, que a denúncia só poderá ser recebida enquanto o denunciado não tiver, por qualquer motivo, deixado definitivamente o cargo. No sistema do direito anterior à Lei 1.079, de 1950, isto é, no sistema das Leis 27 e 30, de 1892, era possível a aplicação tão somente da pena de perda do cargo, podendo esta ser agravada com a pena de inabilitação para exercer qualquer outro cargo (CF de 1891, art. 33, § 30; Lei 30, de 1892, art. $2^{\circ}$ ), emprestando-se à pena de inabilitação o caráter de pena acessória (Lei 27 , de 1892, arts. 23 e 24). No sistema atual, da Lei 1.079, de 1950, não é possível a aplicação da pena de perda do cargo, apenas, nem a pena de inabilitação assume caráter de acessoriedade (CF, 1934, art. 58, § 70; CF, 1946, art. 62, § 30; CF, 1967, art. 44, parágrafo único; EC 1/1969, art. 42, parágrafo único; CF, 1988, art. 52, parágrafo único. Lei 1.079, de 1950, arts. 20, 31, 33 e 34). A existência, no impeachment brasileiro, segundo a Constituição e o direito comum (CF, 1988, art. 52, parágrafo único; Lei 1.079, de 1950, arts. 20, 33 e 34), de duas penas: a) perda do cargo; b) inabilitação, por oito anos, para o exercício de função pública. A renúncia ao cargo, apresentada na sessão de julgamento, quando já iniciado este, não paralisa o processo de impeachment. Os princípios constitucionais da impessoalidade e da moralidade administrativa (CF, art. 37) (STF, MS 21.689, rel. min. Carlos Velloso, julgamento em 16-12-1993, Plenário, DJ de 7-41995).

No Brasil, a revogação dos mandatos políticos já foi matéria suscitada na época do Império. Segundo Ávila ${ }^{15}$, o Decreto expedido pelo Imperador em 16 de fevereiro de 1822, para regular as eleições do Conselho de Procuradores do Estado, "(...)

15 ÁVILA, Caio Márcio de Brito. Recall - a revogação do mandato político pelos eleitores: uma proposta para o sistema jurídico brasileiro. p. 106. 
MARTINS, Urá Lobato; BAPTISTA, Vinicius Ferreira. A adoção do Recall como instrumento de ampliação do controle popular dos mandatos políticos. Revista Eletrônica Direito e Política, Programa de Pós-Graduação Stricto Sensu em Ciência Jurídica da UNIVALI, Itajaí, v.13, n.2, $2^{\circ}$ quadrimestre de 2018. Disponível em: www.univali.br/direitoepolitica - ISSN 1980-7791

previa a possibilidade de perda do mandado do procurador, por meio de eleição, caso este não desempenhasse corretamente suas obrigações."

No entanto, Benevides esclarece que na época em que fora editado o Decreto mencionado, não existia a democracia no sentido contemporâneo (participação livre e soberana). Esclarece, ainda, a referida autora:

Trata-se de um tipo de revogação de mandatos - aliado à ideia do mandato imperativo - e que seria conhecido, a partir da experiência americana, como recall (termo muito lembrado nessa pesquisa). Durou pouco: de 2 de junho de 1822 a 7 de abril de 1823. Mas é a primeira tentativa de intervenção direta do eleitor, na representação parlamentar, de que se tem conhecimento no Brasil. O recall voltaria a ser lembrado nas constituições republicanas estatuais de 1891, como veremos adiante $^{16}$.

Com efeito, nunca foi previsto o instituto do recall na Constituição Federal do Brasil $^{17}$. Porém, foram elaboradas quatro Propostas de Emendas Constitucionais de n. 80/2003; n. 82/2003; n. 73/2005 e n. 477/2010, todas arquivadas em decorrência do final da legislatura.

A PEC n. 80/2003 18 teve o intuito de alterar o art. 14 da Constituição Federal; com a inserção de dois novos institutos da democracia participativa: o direito de revogação (individual e coletivo) e do Veto Popular.

Ainda em 2003, foi apresentada a PEC n. 82/2003 ${ }^{19}$ com a finalidade de alterar os arts. 28, 29, 32, 55 e 82 da Constituição Federal, para que fosse incluído o plebiscito de confirmação de mandato dos representantes eleitos em pleito majoritário, que seria aplicado para o Presidente, Governadores, Senadores e

\footnotetext{
${ }^{16}$ BENEVIDES, Maria Victoria de Mesquita. A cidadania ativa: referendo, plebiscito e iniciativa popular. São Paulo: Ática, 1991. p. 112.

17 Em entrevista concedida a Recondo (2013), o ex-Ministro do Supremo Tribunal Federal, Joaquim Barbosa, mencionou que o instrumento do recall seria adequado para a realidade brasileira.

18 A PEC n. 80/2003 teve a autoria do Senador Antônio Carlos Valadares e outros. No dia 30.03.10 a Comissão de Constituição e Justiça opinou pela prejudicialidade da PEC, em virtude do voto favorável à PEC 73/2005. A referida PEC foi arquivada em decorrência do final da legislatura em 26.12.2014.

${ }^{19}$ A PEC n. 82/2003 teve a autoria do Senador Jefferson Peres e outros. No dia 30.03.10 a Comissão de Constituição e Justiça opinou pela prejudicialidade da PEC, em virtude do voto favorável à PEC 73/2005. A referida PEC foi arquivada em decorrência do final da legislatura no dia 07.01.2011.
} 
MARTINS, Urá Lobato; BAPTISTA, Vinicius Ferreira. A adoção do Recall como instrumento de ampliação do controle popular dos mandatos políticos. Revista Eletrônica Direito e Política, Programa de Pós-Graduação Stricto Sensu em Ciência Jurídica da UNIVALI, Itajaí, v.13, n.2, 20 quadrimestre de 2018. Disponível em: www.univali.br/direitoepolitica - ISSN 1980-7791

Prefeitos. O quórum para subscrição do plebiscito de confirmação seria equivalente a $10 \%$ (dez por cento dos eleitores), sendo que o limite temporal seria a metade do mandato dos Senadores e dos Chefes do Poder Executivo.

$\mathrm{Na}$ proposta referida, foi explicada a inclusão dos Senadores como membros passíveis de sofrer recall:

Mesmo no Brasil, há registro de constituições estaduais que previam o recall, durante a República Velha, relativamente aos mandatos de membros do Poder Legislativo. Tal ocorria em um contexto de voto distrital, sendo impraticável, quanto aos deputados e vereadores, no atual sistema proporcional, mas não em relação aos Senadores, que são eleitores em plebiscitos majoritários. A extensão do mecanismo do recall aos deputados e vereadores pressupõe a adoção do sistema distrital no Brasil, no âmbito de uma ampla reforma política. Nada obsta, no entanto, a aplicação desse instrumento de controle popular relativamente aos Senadores, o que nos levou a inserir, no texto da proposta de Emenda à Constituição que ora apresentamos, dispositivo com esse objetivo. (PEC 82/2003, Diário do Senado Federal no 182, Publicado em 06/11/2003, p. 35.460).

A PEC n. $73 / 2005^{20}$ teve a finalidade de alterar os arts. 14 e 49 da Constituição, bem como acrescentar o artigo 14-A, para que fosse introduzido no ordenamento jurídico brasileiro o instituto denominado recall, que consiste num referendo revocatório do mandado do Presente da República e de Congressistas, após o transcuro do prazo de 1 (um) ano da data da posse nos respectivos cargos, sendo cabível apenas um pedido de revogação durante o mandato.

No que tange ao quórum, a PEC n. 73/2005 estabelece que o referendo deve ser dirigido ao Superior Tribunal Eleitoral, através da assinatura de $2 \%$ do eleitorado nacional, distribuído por sete estados, com não menos cinco décimos por cento em cada um deles ou através da assinatura de $2 \%$ do eleitorado estadual, distribuído

20 A PEC n. 73/2005 teve a autoria do Senador Eduardo Suplicy e outros. No dia 30.03.10 a Comissão de Constituição e Justiça, através do voto do Senador Pedro Simon, proferiu voto favorável à PEC 73/2005. No entanto, a referida PEC foi arquivada em decorrência do final da legislatura, no dia 26.12.2014, com base no art. 332 do Regimento Interno do Senado Federal, sem ter sido apreciada. 
MARTINS, Urá Lobato; BAPTISTA, Vinicius Ferreira. A adoção do Recall como instrumento de ampliação do controle popular dos mandatos políticos. Revista Eletrônica Direito e Política, Programa de Pós-Graduação Stricto Sensu em Ciência Jurídica da UNIVALI, Itajaí, v.13, n.2, $2^{\circ}$ quadrimestre de 2018. Disponível em: www.univali.br/direitoepolitica - ISSN 1980-7791

pelo menos por sete municípios, com não menos de cinco décimos por cento em cada um deles.

A referida PEC faz menção à revogação individual (Presidente, Senadores e Deputados), bem como revogação coletiva que ocorreria com a Dissolução da Câmara dos Deputados, devendo ser convocada nova eleição, a ser realizada no prazo máximo de três meses.

A novidade contida na PEC n. 73/2005 reside na possibilidade de o mandato do Presidente da República ser objeto de referendo revogatório, mediante requerimento da maioria absoluta dos membros do Congresso Nacional, dirigido ao Tribunal Superior Eleitoral. A justificativa para tal inclusão seria a de "(...) criar uma alternativa mais simples e expedita do que o processo normal de crime de responsabilidade, para a destituição de um Presidente que perdeu a confiança do povo e, ao mesmo tempo, entrou em choque com o Poder Legislativo" (PEC n. 73/2005, Diário do Senado Federal no 205, publicado em 10/12/2005, p. 43.635).

Por fim, a referida PEC dispunha que caberia ao Superior Tribunal Eleitoral convocar o referendo revogatório, cabendo também aos Estados, Distrito Federal e Municípios regular em suas Constituições e Leis Orgânicas o referendo revogatório dos mandatos do chefe do Poder Executivo, bem como dos membros do Poder Legislativo.

Ávila ${ }^{21}$ constatou que 0 art. $2^{\circ}$ da PEC 73/2005 estabelece um procedimento diferente do aplicado no sistema norte-americano, razão pela qual afirma que a proposta brasileira foi inspirada no recall norte-americano e no abberunfungsrecht suíço, mas apresenta resultado distinto, conforme afirma:

Verifica-se, pois, que a revogação dos mandatos dos Senadores e do Presidente da República inspirou-se no recall norte-americano. Já no caso da revogação dos mandatos da

21 ÁVILA, Caio Márcio de Brito. Recall - a revogação do mandato político pelos eleitores: uma proposta para o sistema jurídico brasileiro. 
MARTINS, Urá Lobato; BAPTISTA, Vinicius Ferreira. A adoção do Recall como instrumento de ampliação do controle popular dos mandatos políticos. Revista Eletrônica Direito e Política, Programa de Pós-Graduação Stricto Sensu em Ciência Jurídica da UNIVALI, Itajaí, v.13, n.2, $2^{\circ}$ quadrimestre de 2018. Disponível em: www.univali.br/direitoepolitica - ISSN 1980-7791

Câmara dos Deputados, a inspiração obviamente vem do abberunfungsrecht suíço22.

A PEC n. 477/201023 tinha como proposta incluir o artigo 14-A na Constituição Federal, para instituir a Petição revogatória, Petição destituinte e o Plebiscito destituinte.

No caso da Petição Revogatória, deveria ocorrer a subscrição de pelo menos $2 \%$ do eleitorado nacional, distribuído por pelo menos cinco Estados, com não menos $3 \%$ dos eleitores de cada um deles. Tal petição teria como finalidade revogar leis ordinárias, complementares, delegadas, emendas constitucionais e decretos do Poder Legislativo, tendo como limite temporal 8 anos a partir da publicação da norma. A Petição Revogatória seria uma forma do cidadão eleitor impedir normas que considere violação aos seus direitos e garantias

Dentre as Propostas de Emendas Constitucionais mencionadas, a PEC 477 de 2010 foi a única que estabelecia a necessidade de motivação para revogar mandatos. No caso, a Petição Destituinte seria utilizada para decretar a perda de mandato de prefeito, senador e governador, que tivessem cometido, no exercício da função: improbidade administrativa; malversação e desvio de recursos; atos incompatíveis com exercício responsável, ético e transparente da função; e contrariedade aos princípios constitucionais republicanos. O quórum necessário seria a subscrição de $10 \%$ do eleitorado do estado ou município do representante em questão. Ambas petições seriam encaminhadas ao Supremo Tribunal Federal. Caso fosse proferido parecer conclusivo admitindo a Petição Revogatória, a revogação da norma teria efeito imediato, não cabendo recurso.

No caso da Petição Destituinte, ocorreria um plebiscito, no prazo máximo de 60 dias após o parecer favorável do Supremo Tribunal Federal, sendo que a perda do mandato seria decretada caso existisse a manifestação da maioria absoluta dos

\footnotetext{
22 ÁVILA, Caio Márcio de Brito. Recall - a revogação do mandato político pelos eleitores: uma proposta para o sistema jurídico brasileiro. p. 110.

${ }^{23}$ A PEC n. 477/2010 teve a autoria do Deputado Rodrigo Rollemberg, também foi arquivada em decorrência do final da respectiva legislatura (arquivada em 31.01.2011).
} 
MARTINS, Urá Lobato; BAPTISTA, Vinicius Ferreira. A adoção do Recall como instrumento de ampliação do controle popular dos mandatos políticos. Revista Eletrônica Direito e Política, Programa de Pós-Graduação Stricto Sensu em Ciência Jurídica da UNIVALI, Itajaí, v.13, n.2, $2^{\circ}$ quadrimestre de 2018. Disponível em: www.univali.br/direitoepolitica - ISSN 1980-7791

votos válidos. Neste caso, no prazo máximo de 48 horas, o substituto legal assumiria o mandato.

A Carta Magna afirma que todo poder emana do povo, logo, é patente a legitimidade de o povo destituir o representante do poder. Sendo assim, a possiblidade de revogar mandatos possibilitaria um maior controle popular no sentido de verificar se as plataformas políticas e as propostas feitas foram, de fato, cumpridas. No entanto, todas as PEC's mencionadas foram arquivadas em decorrência do final da legislatura. Portanto, ainda é um assunto a ser debatido.

Ao observar a proposta de agregar à Constituição o instituto do Recall, como parte intrínseca do processo eleitoral e governamental brasileiro, alguns aspectos devem ser considerados, no âmbito da defesa argumentativa de se afastar do Legislativo qualquer possibilidade de evocação, controle, monitoramento ou avaliação desse instituto. O Recall, enquanto base processual avaliativa do Governo, deve ser institucionalizado pelo sistema eleitoral sem qualquer contato com o Executivo e Legislativo, uma vez que pode padecer pela contaminação e possível desagregação por entre atores vinculados.

O Recall deve ser periodizado e regulamento para execução na metade do mandato do cargo público eletivo, de forma a permitir a avaliação da execução das proposições dos candidatos, os resultados de sua atuação parlamentar ou governamental objetivando análise sobre mérito. Todavia, este instituto deve levar em consideração alguns aspectos do fisiologismo brasileiro, no que se refere ao sistema governamental e eleitoral do país.

Castro e Nunes ${ }^{24}$, Chaia e Teixeira ${ }^{25}$ e Filgueiras ${ }^{26}$ permitem compreender algumas questões a serem consideradas no âmbito do processo histórico, político e institucional brasileiro, notadamente fragilizado pelo pouco aproveitamento dos

24 CASTRO, Mônica Mata Machado de; NUNES, Felipe. Candidatos corruptos são punidos? Accountability na eleição brasileira de 2006. Opinião Pública, Campinas, vol. 20, no 1, abril, 2014, p. 26-48.

25 CHAIA, Vera; TEIXEIRA, Marco Antonio. Democracia e escândalos políticos. São Paulo em Perspectiva, vol. 15, n. 4 2001, p. 62-75.

26 FILGUEIRAS, Fernando. A tolerância à corrupção no Brasil: uma antinomia entre normas morais e prática social. Opinião Pública, Campinas, vol. 15, no 2, Novembro, 2009, p.386-421. 
MARTINS, Urá Lobato; BAPTISTA, Vinicius Ferreira. A adoção do Recall como instrumento de ampliação do controle popular dos mandatos políticos. Revista Eletrônica Direito e Política, Programa de Pós-Graduação Stricto Sensu em Ciência Jurídica da UNIVALI, Itajaí, v.13, n.2, $2^{\circ}$ quadrimestre de 2018. Disponível em: www.univali.br/direitoepolitica - ISSN 1980-7791

sistemas democráticos de participação popular, quebrados especificamente pela Ditadura Militar e recuperados lentamente com a Constituição de 1988.

A primeira questão se refere à síndrome de desconfiança e indiferença, onde se apresentam dois lados: em uma vertente, o cidadão brasileiro, na postura de eleitor, não possui confiança na classe política, seja devido aos escândalos políticos relativos ao gerenciamento da res publica, seja na capacidade em si, da classe política elucidar e resolver problemas da ordem pública que afetem a coletividade. A segunda vertente se volta à perspectiva de uma não percepção de corrupção em atitudes da classe política, no sentido desta engendrar esquemas de corrupção que envolvam indiretamente a intervenção sobre a realidade social que, de fato, melhore as vidas das pessoas (popularmente, tal processo desta classe política é denominado "rouba mas faz"), assim como no entendimento de uma não percepção de corrupção em pequenas atitudes corriqueiras ou consideradas de "menor" dano, ou seja, implica-se um contexto de tolerância, onde se misturam a vida pública e a vida privada.

A segunda questão se volta ao fato de que as pessoas não sabem o que acontecem no que acontece na caixa preta no Legislativo, onde a classe política se protege em negociações em determinados processos políticos. Como os cidadãos pouco sabem sobre o que realmente ocorre nos centros decisórios do poder, os mesmos desconfiam cada mais da classe política, em termos de decisões sensatas e claras. Neste ponto, o Judiciário tem agido como uma "lanterna", evidenciando esquemas de corrupção dentro do Legislativo, o que clarifica as mazelas do Poder Legislativo e o coloca em confronto diversas vezes com o Judiciário.

A terceira questão envolve a distância temporal entre a observação de resultados e as eleições, onde geralmente, a população não tem o costume de avaliar as ações de gestores públicos e, costumeiramente, guarda as impressões próximas ao período eleitoral - período estratégico em que gestores se utilizam de artifícios como inaugurações de obras e equipamentos, por exemplo, para evidenciarem esforço gerencial e de melhoria de bem-estar à população.

A quarta questão se situa com a desigualdade social e estrutural em cidades que dificultam acesso à informação e exercício do controle social. Este ponto é 
MARTINS, Urá Lobato; BAPTISTA, Vinicius Ferreira. A adoção do Recall como instrumento de ampliação do controle popular dos mandatos políticos. Revista Eletrônica Direito e Política, Programa de Pós-Graduação Stricto Sensu em Ciência Jurídica da UNIVALI, Itajaí, v.13, n.2, $2^{\circ}$ quadrimestre de 2018. Disponível em: www.univali.br/direitoepolitica - ISSN 1980-7791

fundamental uma vez que as condições materiais, de fato, permitem ou não o claro exercício do controle social. Municípios de pequeno porte, por exemplo, não possui estrutura logística de transporte adequados que permitam aos cidadãos participarem, por exemplo, de audiências públicas nas Câmaras Municipais frequentemente. Um outro exemplo está na transparência das contas públicas do Município em seu website onde, regularmente, gestores evocam a infraestrutura técnica e financeira como impeditivos da publicização de dados e informações para acesso público - aliás, o próprio acesso pela população já é uma dificuldade notável.

Por fim, a variável tempo na avaliação do candidato eleito é a quinta questão fundamental no processo de punição da classe política. Tendo em mente que quanto mais se demora o acionamento dos mecanismos de avaliação de um político ou gestor público (as eleições costumam funcionar neste sentido como mecanismo), maior é a tendência do cidadão não o punir por determinada ação que ocasione má gestão. Quanto menor o tempo, maior a tendência para o eleitor punir seu político com uma não reeleição.

Todas estas cinco questões apontam, desta forma, para três elementos básicos que indicamos como essenciais para se afastar o instituto do Recall dos Poderes Legislativo e Executivo: o Clientelismo, o Assistencialismo ou Paternalismo; e a Falta de Cultura Participativa e Fiscalizatória, notórios em âmbito brasileiro. O objetivo de fazermos esta defesa de distanciamento é que, tendo observado as cinco questões indicadas, é essencial evitar o acionamento indiscriminado do recall, capaz de provocar instabilidade política quando acionado sem bases constitucionais satisfatórias.

Existe um fisiologismo na política brasileira que faz com que a população se afaste da Política e do jogo democrático, uma vez que agentes políticos apresentam comportamentos danosos à sociedade. Ao mesmo tempo, a cultura do clientelismo atrelado ao paternalismo evidencia uma leniência da população para com agentes políticos que, independentemente de comprovados crimes, não são punidos no processo eleitoral. Ainda nesta conjuntura, agentes políticos empreendem 
MARTINS, Urá Lobato; BAPTISTA, Vinicius Ferreira. A adoção do Recall como instrumento de ampliação do controle popular dos mandatos políticos. Revista Eletrônica Direito e Política, Programa de Pós-Graduação Stricto Sensu em Ciência Jurídica da UNIVALI, Itajaí, v.13, n.2, $2^{\circ}$ quadrimestre de 2018. Disponível em: www.univali.br/direitoepolitica - ISSN 1980-7791

negociações escusas que são evidenciadas pela Mídia e que, conforme o lapso temporal, a tendência é a de não punição.

Há ainda de se considerar a instabilidade dos próprios agentes políticos no âmbito do recall. Como observado no recente momento brasileiro com o processo de Impeachment da Presidente Dilma Rousseff, um ambiente instável em que o instituto do Recall não seja constitucionalmente periodizado e afastado do Legislativo e Executivo, tal ambiente pode provocar o acionamento deste instituto sem fundamentação constitucional, desestabilizando o sistema político. Agentes políticos podem induzir a população a acionar o instituto devido à instabilidade geral, incutindo na sociedade (em um processo difundido e manipulado pela Mídia) uma necessidade de afastamento sem fundamentação. O mandato político necessita de tempo para começar a produzir frutos relativos às intervenções estatais na sociedade e, desta forma, o instituto do recall acionado de forma indevida, ocasiona ainda mais instabilidade em um ambiente já instável.

\section{CONSIDERAÇÕES FINAIS}

A proposta de Gestão Pública com protagonismo social percebe uma diferente interpretação acerca dos mecanismos de participação democrática e se constrói sobre a ideia do interesse público, a ideia de gestores públicos a serviço da Cidadania. Sustenta que a gestão pública deve começar com o reconhecimento de que a existência de uma cidadania engajada e esclarecida é o fundamento para a governança democrática. Esta forma de ver e tratar a cidadania reconhece que o comportamento humano não é apenas questão de autointeresse, mas também envolve valores, crenças e preocupação com os outros. Os cidadãos são capazes de atuar juntos em busca do bem maior. A cidadania não se resume aos direitos e deveres elencados na Constituição Federal em níveis cívico, político e social, mas à apropriação em si e para si dos cidadãos e entre os cidadãos dos espaços de deliberação pública e política sobre a tomada de decisão na formulação, não só de políticas públicas e programas governamentais, mas da intervenção estatal sobre a vida pública.

O principal desafio neste contexto é o de ampliar o processo deliberativo e participativo na criação de uma dinâmica prática à participação política, pois nem 
MARTINS, Urá Lobato; BAPTISTA, Vinicius Ferreira. A adoção do Recall como instrumento de ampliação do controle popular dos mandatos políticos. Revista Eletrônica Direito e Política, Programa de Pós-Graduação Stricto Sensu em Ciência Jurídica da UNIVALI, Itajaí, v.13, n.2, $2^{\circ}$ quadrimestre de 2018. Disponível em: www.univali.br/direitoepolitica - ISSN 1980-7791

toda forma de intervenção política pode ser considerada "deliberativa", haja visto a atuação de grupos de interesse que possuem uma lógica de ação coletiva individualizada que não observam a coletividade e o "bem público". O engajamento político é necessário à construção deliberativa da democracia, todavia, o mesmo é um processo de construção social.

O instituto do recall é mecanismo de salvaguarda para a própria população para que esta tenha competência para avaliar mandatos de políticos, de forma periódica e séria, desatrelada do sistema político e dos Poderes Executivos e Legislativo. Todavia, isso necessita de amadurecimento do aparelho democrático brasileiro, notadamente caracterizado pelo fisiologismo que existe no sistema político. Evidencia-se, assim, que o recall representaria um importante instrumento democrático, viabilizador de um maior controle do povo em relação aos mandatos políticos, considerando que o impeachment ganhou contornos constitucionais restritos.

\section{REFERÊNCIA DAS FONTES CITADAS}

ÁVILA, Caio Márcio de Brito. Recall - a revogação do mandato político pelos eleitores: uma proposta para o sistema jurídico brasileiro. 2009. 152 f. Tese (Doutorado em Direito) - Faculdade de Direito, Universidade de São Paulo, São Paulo, 2009. Disponível em: $<h t t p: / / w w w . t e s e s . u s p . b r / t e s e s / d i s p o n i v e i s / 2 / 2134 / t d e-08032010-094820 / p t-$ br.php>. Acesso em 10 de maio de 2018.

BENEVIDES, Maria Victoria de Mesquita. A cidadania ativa: referendo, plebiscito e iniciativa popular. São Paulo: Ática, 1991.

BOLÍVIA. Constituição Política do Estado da Bolívia. Aprovada mediante referendo realizado no dia 25 de janeiro de 2009. Disponível em: <https://bolivia.infoleyes.com/norma/469/constituci\%C3\%B3n-pol\%C3\%ADticadel-estado-cpe>. Acesso em 10 de maio de 2018.

BONAVIDES, Paulo. Ciência Política. 18 ed. São Paulo: Malheiros, 2011.

BRASIL. Congresso Nacional. Proposta de Emenda à Constituição Federal n. 80/2003. Altera a redação do artigo 14 da Constituição Federal, inserindo incisos que criam dois novos institutos da democracia participativa, o Direito de Revogação e o Veto Popular. Disponível em: <https://www25.senado.leg.br/web/atividade/materias/-/materia/63404>. Acesso em 10 de maio de 2018. 
MARTINS, Urá Lobato; BAPTISTA, Vinicius Ferreira. A adoção do Recall como instrumento de ampliação do controle popular dos mandatos políticos. Revista Eletrônica Direito e Política, Programa de Pós-Graduação Stricto Sensu em Ciência Jurídica da UNIVALI, Itajaí, v.13, n.2, $2^{\circ}$ quadrimestre de 2018. Disponível em: www.univali.br/direitoepolitica - ISSN 1980-7791

BRASIL. Congresso Nacional. Proposta de Emenda à Constituição Federal n. 82/2003. Altera os arts. $28,29,32,55$ e 82 da Constituição, para prever o plebiscito de confirmação de mandato dos representantes do povo eleitos em pleito majoritário.

Disponível em: <https://www25.senado.leg.br/web/atividade/materias/-/materia/63682>. Acesso em 10 de maio de 2018.

BRASIL. Congresso Nacional. Proposta de Emenda à Constituição Federal n. 73/2005. Altera dispositivos dos artigos 14 e 49 da Constituição Federal e acrescenta o artigo 14-A, (institui o referendo revocatório do mandato de Presidente da República e de Congressista). Disponível em: <https://www25.senado.leg.br/web/atividade/materias/-/materia/76146>. Acesso em 10 de maio de 2018.

BRASIL. Congresso Nacional. Proposta de Emenda à Constituição Federal n. 477/2010. Acrescenta o art. 14-A na Constituição Federal para instituir a Petição Revogatória, a Petição Destituinte e o Plebiscito Destituinte e dá outras providências. Disponível em: $<$ http://www.camara.gov.br/proposicoesWeb/fichadetramitacao?idProposicao=4 72552>. Acesso em 10 de maio de 2018.

BRASIL. Supremo Tribunal Federal. MS 21.689, Rel. Min. Carlos Velloso, julgamento em 16-12-1993, Plenário, DJ de 7-4-1995. Disponível em: <http://www.stf.jus.br/arquivo/cms/sobrestfconhecastfjulgamentohistorico/anex o/ms21689.pdf >. Acesso em 10 de maio de 2018.

CASTRO, Mônica Mata Machado de; NUNES, Felipe. Candidatos corruptos são punidos? - Accountability na eleição brasileira de 2006. Opinião Pública, Campinas, vol. 20, no 1, abril, 2014, p. 26-48. Disponível em: $<$ http://www.scielo.br/scielo.php?script=sci_arttext\&pid=S0104-

$62762014000100002>$. Acesso em 10 de maio de 2018.

CHAIA, Vera; TEIXEIRA, Marco Antonio. Democracia e escândalos políticos. São Paulo em Perspectiva, vol. 15, n. 4 2001, p. 62-75. Disponível em: $<$ http://www.scielo.br/scielo.php?script=sci_arttext\&pid=S0102-

$88392001000400008>$. Acesso em 10 de maio de 2018.

COLÔMBIA. Constituição Política da Colômbia. Aprovada em 04 de julho de 1991.

em:

<http://www.alcaldiabogota.gov.co/sisjur/normas/Norma1.jsp?i=4125>. Acesso em 10 de maio de 2018.

COLÔMBIA. Lei n. 134. Regulamenta os mecanismos de participação do cidadão. Publicada em 31 de maio de 1994. Disponível em: <http://www.alcaldiabogota.gov.co/sisjur/normas/Norma1.jsp?i=330>. Acesso em 10 de maio de 2018.

CÓRDOBA. Constituição da Província de Córdoba. Aprovada em 26 de abril de 1987. 
MARTINS, Urá Lobato; BAPTISTA, Vinicius Ferreira. A adoção do Recall como instrumento de ampliação do controle popular dos mandatos políticos. Revista Eletrônica Direito e Política, Programa de Pós-Graduação Stricto Sensu em Ciência Jurídica da UNIVALI, Itajaí, v.13, n.2, $2^{\circ}$ quadrimestre de 2018. Disponível em: www.univali.br/direitoepolitica - ISSN 1980-7791

<http://web2.cba.gov.ar/web/leyes.nsf/\%28vLeyesxNro\%29/CP00?OpenDocum ent>. Acesso em 10 de maio de 2018.

CUBA. Constituição da República de Cuba. Proclamada em 24 de fevereiro de 1976. Disponível em: <http://www.cuba.cu/gobierno/cuba.htm>.

CUBA. Lei n. 89. Regulamenta a revogação dos mandatos dos eleitos ao poder. Promulgada em 10 de setembro de 1999. Disponível em: <http://juriscuba.com/wp-content/uploads/2015/10/Ley-No.-089-De-la-

Revocacion-del-Mandato-del-Poder-Popular.pdf $>$.

DALLARI, Dalmo de Abreu. Elementos de Teoria Geral do Estado. 25. ed. atual. São Paulo: Saraiva, 2005.

EQUADOR. Constituição da República do Equador. Publicada em 20 de outubro de 2008.2 Disponível em: <https://www.asambleanacional.gob.ec/es/contenido/constitucion-de-larepublica-del-ecuador $>$. Acesso em 10 de maio de 2018.

FILGUEIRAS, Fernando. A tolerância à corrupção no Brasil: uma antinomia entre normas morais e prática social. Opinião Pública, Campinas, vol. 15, no 2, novembro, 2009, p.386-421. Disponível em: $<$ http://www.scielo.br/scielo.php?script=sci_arttext\&pid=S0104-

$62762009000200005>$. Acesso em 10 de maio de 2018.

PERU. Constituição Política do Peru. Ratificada em referendo em 31 de outubro de $1993 . \quad$ Disponível em: <http://spij.minjus.gob.pe/content/publicaciones_oficiales/img/ConstitucionPolitica-2016.pdf>. Acesso em 10 de maio de 2018.

RECONDO, Felipe. Joaquim Barbosa defende recall de candidatos eleitos. Estadão, Brasília, 25 jun. 2013. Disponível em: <http://www.estadao.com.br/noticias/nacional,joaquimbarbosa-defende-recallde-candidatos-eleitos,1046908,0.htm >. Acesso: 11 de maio de 2016.

SOUZA, Raphael Ramos Monteiro; VIEIRA, José Ribas. Recall, democracia direta e estabilidade institucional. Revista de Informação legislativa, v. 51, n. 202, p. 43-57, abr./jun. 2014. Disponível em: $<$ http://www2.senado.leg.br/bdsf/handle/id/503036>. Acesso em 10 de maio de 2018.

VEnEZUELA. Constituição da República Bolivariana da Venezuela. Promulgada em 15 de dezembro de 1999. Disponível em <http://www.mpptaa.gob.ve/publicaciones/leyes-y-reglamentos/constitucion-dela-republica-bolivariana-de-venezuela>. Acesso em 10 de maio de 2018.

Recebido em: 06/08/2016

Aprovado em: 10/05/2018 